\title{
Prospects for Extraction of Useful Elements Out of the Brines of the Pre-Carpathian Downfold
}

\author{
Sophia KOSHARNA ${ }^{1 *}$, Yana MALKOVA ${ }^{2}$, Lubica KOZAKOVA ${ }^{3}$, Zuzana FRANCOVA $^{4}$, \\ Monika NADOVA KROSLAKOVA ${ }^{5}$ and Zuzana SEDLAKOVA ${ }^{6}$
}

Authors' affiliations and addresses:

${ }^{1}$ Taras Shevchenko National University of Kyiv, ERI "Institute of Geology", Department of Hydrogeology and Engineering Geology, Vasylkivska str. 90, 03022, Kyiv, Ukraine

e-mail: sofiia.kosharna@ukr.net

${ }^{2}$ State Institution "The Institute of Environmental Geochemistry of National academy of sciences of Ukraine", Palladina Ave. 34a, 03680, Kyiv, Ukraine e-mail: malkovayanakiev@gmail.com

3,6 Technical university of Kosice, Faculty of Mining, Ecology, Process Control and Geotechnologies, Institute of Earth Resources, Letna 9, Kosice 042 00, Slovakia

e-mail: lubica.kozakova@tuke.sk

e-mail: zuzana.sedlakova@tuke.sk

${ }^{4}$ University of Economics in Bratislava, Faculty of Commerce, Department of Marketing, Dolnozemská cesta 1, 85235 Bratislava 5, Slovakia

e-mail: zuzana.francova@euba.sk

${ }^{5}$ University of Economics in Bratislava, Faculty of Commerce, Department of Services and Tourism, Dolnozemská cesta 1, 85235 Bratislava 5, Slovakia e-mail: monika.kroslakova@euba.sk

\section{*Correspondence:}

Sophia Kosharna, Taras Shevchenko National University of Kyiv, ERI "Institute of Geology", Department of Hydrogeology and Engineering Geology, Vasylkivska str. 90, 03022, Kyiv, Ukraine

e-mail: sofiia.kosharna@ukr.net

Funding information:

This paper has been produced benefiting from the KEGA 034EU-4/2020 "Content and technical innovation approaches to teaching regional tourism"

How to cite this article:

Kosharna, S., Malkova Y., Kozakova, L.,

Francová, Z., Nad’ová Krošláková, M. and

Sedláková Z. (2021). Prospects for extraction of useful elements out of the brines of the Pre-

Carpathian downfold. Acta Montanistica Slovaca, Volume 26 (4), 834-842

DOI:

https://doi.org/10.46544/AMS.v26i4.19

\begin{abstract}
Pre-Carpathian Downfold is an important strategic centre for the extraction of potassium salts. The unique ratios of salt minerals found within its deposits have no analogues in the world. And the obtained, of their processing, high-quality products have always been in high demand. However, the primary resources of the largest deposits were almost depleted more than a decade ago, and the formed post-mining territories became a source of accumulation of negative environmental impacts. To cover the current national demand and to increase Ukraine's competitiveness in the world market, it is necessary to process secondary sources containing salt components such as tailings, storage tanks, sludge storage. A new approach and especially more efficient technological procedures are needed for balancing economic and environmental indicators and the brine processing of these secondary sources. From an environmental and economic point of view, membrane technologies use is considered to be more appropriate than old brine evaporation systems. This work investigates the possibilities of such processing regarding brines of the Dombrowsky quarry of Kalush-Golinsky deposit. According to the results, advantageous key financial indicators of the simulated project were obtained. The results of the study are described with respect to the possibility of implementing such an approach for solving a set of environmental and economic tasks, such as stabilizing the level of environmental security and increasing the macroeconomic performance of the country.
\end{abstract}

\section{Keywords}

Pre-Carpathian Downfold, Dombrovsky quarry, ecological balance of territories, brines, annual discount rate, useful components. 


\section{Introduction}

The principle of interdependence between natural resources and the level of economic well-being has always determined the level of development of any country in the world. But at the same time, active development of subsoil, which consistently goes through the stages of geological research, intensive use and post-mining (depletion and liquidation of deposits), has its price. Recently, it has become clear that environmental problems in mining regions in the final stages of development critically worsen living conditions and do not contribute to state growth in terms of sustainable development. Such a situation is obvious in Ukraine as well as in other countries whose economies are associated with mining. A typical example is the territory of the Pre-Carpathian Downfold in the west of the country. Geologically, it is a young alpine region of crustal subsidence, which has long been one of the strategic centres for the extraction of various minerals and where many objects are now recorded in the post-mining stage.

Among others, areas of extraction of potassium salts become the main focus. This is due to the significant variety and unique ratios of salt minerals found within the downfold and having no analogues in the world. Most of the known salt deposits, as a rule, have from two to four minerals (halite and anhydrite are always present, with common addition of sylvin and carnallite), while in the Pre-Carpathian ones, up to two dozen can be found. All of them are chlorides, one mineral - kainite belongs to chloride sulfates, the rest are aqueous and anhydrous sulfates of sodium, potassium, magnesium and calcium. In addition to these minerals, strontium salts and, in small quantities, borates were found in the saline stratum.

Taking into account the above-mentioned, the abandoned salt mining areas should be considered not only as of the root cause of the systematic accumulation of negative environmental impacts but also as a potential resource source.

\section{Analysis of recent research}

Over the last decade, one of the most priority components of Ukraine's Strategy for Environmental Safety (Strategy for Environmental Safety and Climate Change Adaptation) has been the development of precautionary measures to prevent environmental catastrophe due to the activities of mining companies. Traditionally, in order to balance and improve the environment, in particular in the post-mining regions, the introduction of a set of measures for the rehabilitation of disturbed and polluted lands and water bodies is proposed. Thus, in their place, sustainable, environmentally friendly systems are created, as they will contribute to the socio-economic revival of the country. And first of all, it concerns those territories where ecological safety of the geological environment in zones of influence of the mining enterprises is connected with negative consequences of technogenic activation of karst. The latter is a distinguishing feature of places of development of potash deposits, significant deposits of which are located within the Pre-Carpathian Downfold.

Potassium salts within the established structure, in particular at such important, though not currently operating, facilities as Kalush-Golynsky, Stebnytsky and Solotvynsky deposits have become the root cause of a number of environmental problems, which are becoming more widespread every year. It should be noted that the development of dangerous exogenous processes, as well as regular discharges of drainage waters into the surface river runoff, have become an urgent problem. The main danger from their input from reservoirs and sludge reservoirs of potash deposits is the salt content, which significantly exceeds the permissible norms. This leads to a violation of geochemical (landscape-geochemical), hydrogeological and eco-geological parameters of the geological environment, which is significantly reflected in the welfare of the population, bringing the need to solve the problem to the list of priorities (Dovhyi and Korzhnev, 2013; Malovanyi and Savchuk, 2013; Maniuk, 2009; Maniuk et al., 2009).

At the present stage of research, given the complexity and urgency of the development of dangerous environmental and geological processes in the west of the country, many scientists are trying to give a prognostication assessment of this development and investigate the real threatening situation. In particular, the results of geophysical monitoring of the geological environment and the forecast of the development of dangerous geological processes are described in the works of Kuzmenko E.D., Bagriy S.M., Vdovin O.P., Shtogrin M.V., Buchinsky V.A., and others (Kuzmenko and Bagriy, 2009, 2015). Pavlyuk V.I. studied mancaused disturbed saline molasses of Precarpathian to determine zones of geoecological risk in man-caused disturbed areas of salt deposits, where negative karst processes and other exogenous geological processes are observed or may occur. (Pavlyuk, 2010). The issues of ecological safety in the process of development of potassium salt deposits were also studied by such researchers as Manyuk, Semchuk Y.M., Rudko H.I., and others (Maniuk and Semchuk, 2007; Rudko and Petryshyn, 2014).

In order to be more specific, the Kalush district in Pre-Carpathian, where one of the most famous deposits of potassium salts are located - Kalush-Golynsky, was chosen as the object of the research. Peculiarities of its saline rocks, as well as its influence on the geological environment, have been the subject of research for such modern scientists as Holovchak V., Zozulya I., and others. The analysis of their work allowed us to single out, 
among others, the main factor, the impact of which covers almost all elements of the biosphere, namely the excessive amounts of brine inherited from mining in previous years.

In order to be more specific, the Kalush district in Pre-Carpathian, where one of the most famous deposits of potassium salts are located - Kalush-Golynsky, was chosen as the object of the research. Peculiarities of its saline rocks, as well as its influence on the geological environment, have been the subject of research for such modern scientists as Holovchak V., Zozulya I., and others (Holovchak, 2012). The analysis of their work allowed us to single out, among others, the main factor, the impact of which covers almost all elements of the biosphere, namely the excessive amounts of brine inherited from mining in previous years.

Thus, for decades of active research of the zone of technogenesis of the salt-mining complex in the Carpathian region, in particular the Kalush-Holynsky deposit, the researchers have identified the following problems:

- accumulated 10 million $\mathrm{m}^{3}$ of brine in the quarry, and one of the tailings poses a real threat of breaking the dams of these hydraulic structures with their subsequent entry into the water system of the Dniester River (Maniuk et al., 2009, Chonka et al., 2019);

- regular infiltration of brines from these structures provoked a violation of the natural conditions of supply, transit and unloading of groundwater and surface water, including salinization of groundwater on an area of more than 1000 hectares, which were removed from the land-use system (Holovchak, 2012);

- the threat of intrusion of highly concentrated brines in the Dombrovsky quarry with a drinking aquifer, which is uploaded into the cleanest river in Ukraine, Limnytsia (Malkova et al., 2021);

- at the same time, the annual increase in the concentration of brines in the accumulation basins is recorded, where along with the safe components of highly mineralized waters, which will potentially pollute the sources of drinking water supply in the Dniester and Tysa basins. (Kosharna, 2020);

- massive and continuous infiltration of saltwater also causes a reduction in the duration of safe operation of water supply and sewerage networks, foundations of industrial and residential buildings, due to increased aggressiveness of groundwater and soils as well (Zhuravel et al., 1998).

Given the above list, the fact of increasing environmental risk as a result of the impact of post-mining facilities becomes critical for the Transcarpathian, Lviv, Ivano-Frankivsk regions. Moreover, it is caused by the fact that the drinking water supply of residential areas of these territorial units is to a large extent provided by coastal water intakes from the rivers mentioned above.

The trend of the study area development does not correspond to the concept of "sustainable development" defined by the International Commission on Environmental Problems (1987). The approved definition describes a development that "leads to the satisfaction of the urgent needs of society without reducing the ability of future generations to meet their needs." This means that development should be carried out in such a way as not only to minimize the negative consequences of natural resources depletion and deterioration of the environment in order to preserve them for future generations but also in the social and economic area (Amosha et al., 2017). From an economic point of view, the permanent attraction of financial resources to take measures to eliminate all damage to the environment without addressing its root cause is not very effective.

Modern programs for sustainable development of the mining industry are trying to develop in cases where the economy is closely linked to the mineral complex. These programs can either aim to solve a specific problem or improve the general living conditions of the local population. There are many examples of such situations, in particular in France (Cojean et al., 2005), Portugal (Sardinha et al., 2010), the Czech Republic (Sklenicka et al., 2004) and others. Economic, ecological and social conditions of every mining region of Ukraine are also individual depending on the type of mineral raw materials, type of area, its geology, climate and much more. Therefore, programs for their ecological rehabilitation and further development should be individual, taking into account the specifics of the regions (Korzhnev et al., 2021). This also applies to the Precarpathian Downfold, where the object of study is located.

It should be noted that in addition to surveys aimed at identifying all existing environmental problems, the research territory of the study was a location for the work related to the analysis of salt components related to salt extraction and salt processing sites (dumps, tailings, storage tanks, sludge storage, flooded mines). The results show that the aquatic environment can get the same components that are in all-natural waters and form their macro-component composition and type, but the concentrations in which they fall are quite high, often reaching industrial values. Furthermore, the change of the natural water type mainly depends on this.

Given the above, the purpose of this study is:

- proving the feasibility of using brines of the Kalush-Golinsky deposit as additional raw materials to improve the ecological and economic situation in the region;

- checking the economic efficiency of the introduction of modern technological ways of brine management through experiment. 


\section{Presentation of the main material}

The mineral resource base (SME) should provide a balanced structure and rational use of available resources within individual districts on a regional scale. And the Pre-Carpathian Downfold is the region where there are all the prerequisites for a qualitative balance of economically viable activities with the preservation of the natural environment as a national heritage. An essential component of such a balance can be the concept of extracting useful components from brines and processing them into a marketable product.

According to the results of field and experimental work (Malkova et al., 2020), analysis of environmental monitoring data and economic aspects, the Kalush-Golynsky field was identified by the authors as one of industrial and economic interest. This is due to the following reasons:

1. Significant contents of potassium-magnesium salts, bromine, and less often boron are established in salt waters and brines of the studied object. Their extraction, processing, and distribution can positively affect the scarce production in Ukraine.

2. Ecological indicators of a significant impact of the liquidated field on the environment are significantly reflected at the state statistical reporting level.

3. In recent years, across the country, we can observe a systematic decrease in exports of such products as industrial salt and mineral fertilizers (including potassium) (Figs. 2, 4) with a simultaneous increase in their imports (data from SFS of Ukraine) (Figs. 1,3). And this indicates the inability to meet national demand by national production capacity.

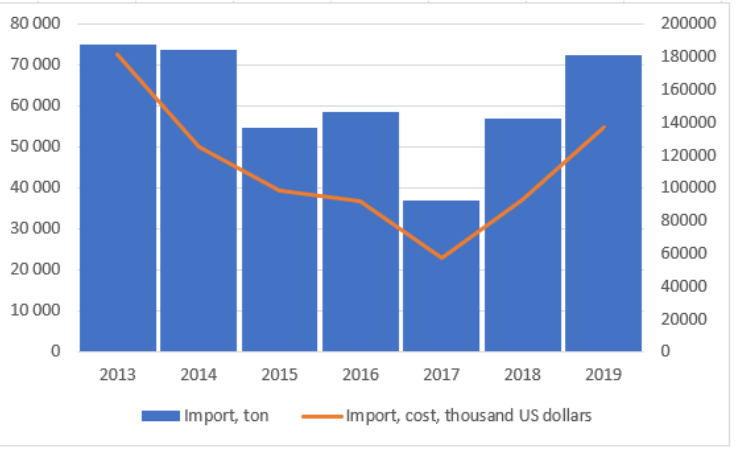

Fig. 1. Import of potash mineral fertilizers

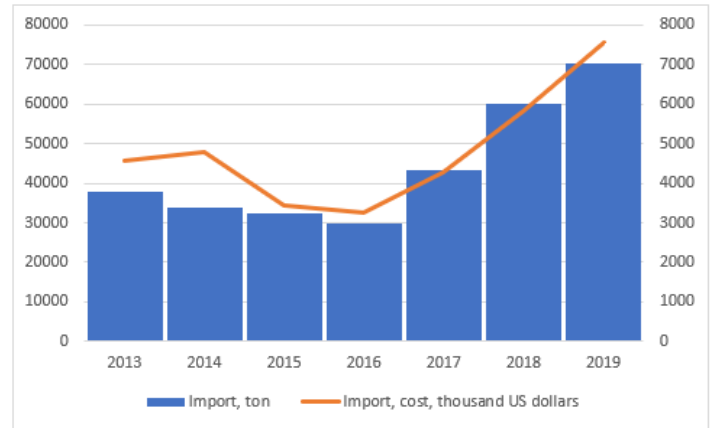

Fig. 3. Import of technical salt, pure sodium chloride, seawater

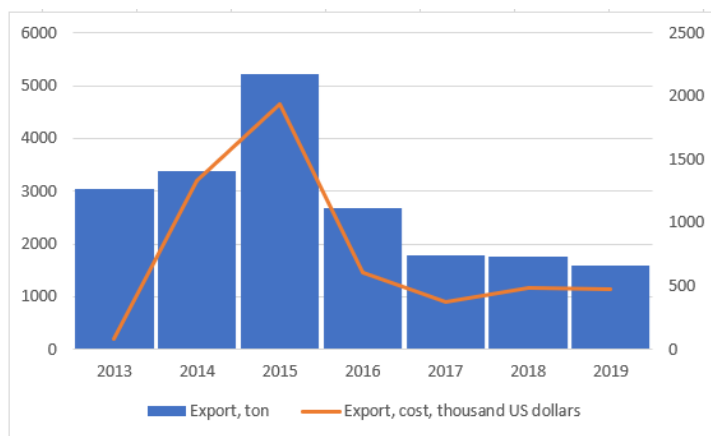

Fig. 2. Export of potash mineral fertilizers

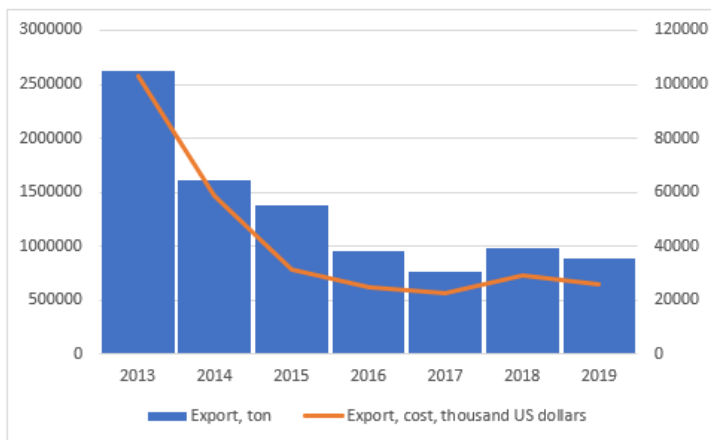

Fig. 4. Export of technical salt, pure sodium chloride, seawater

The research tracks trends in global consumption of potash fertilizers used in agriculture over the past 10 years. The forecast for the next 5 years is made based on the collected statistical data (Fig. 5). 


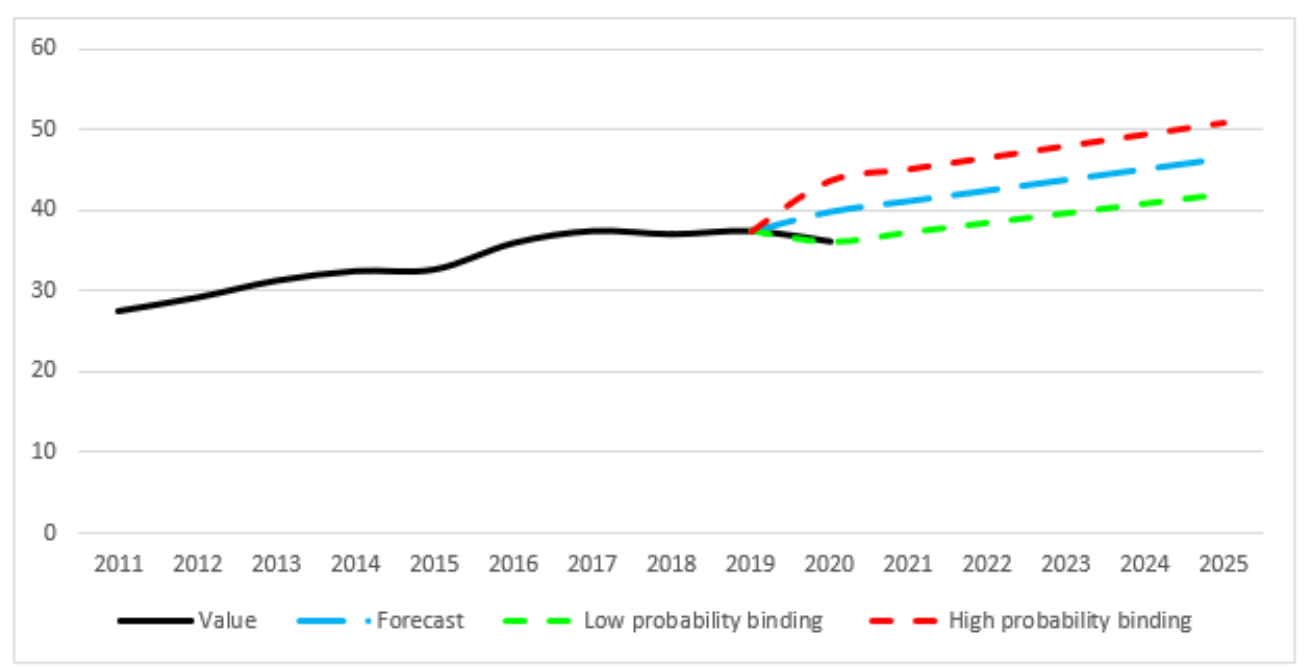

Fig. 5. Forecast of the dynamics of the consumption of potash fertilizers in the world

The obtained results give grounds to believe that even under conditions of low probabilities, the values will increase, and therefore the country's need to provide for itself by minimizing import expenditure will not lose its relevance. Therefore, the introduction of the above-mentioned concept of brine processing is an obvious opportunity to influence the development of this industry qualitatively. The latter demonstrates significant economic benefits in a situation of crisis.

In view of the above, it is reasonable to consider investing in projects aimed at increasing the country's raw material potential in relation to the above-mentioned areas. This is due not only to the environmental aspect, which includes the ability to significantly affect the degree of salinity of the surrounding areas, thereby reducing the risk of environmental catastrophe, as well as the economic one.

The evidence base of such statements was the results of research conducted on the Dombrovsky quarry of the Kalush-Golynsky deposit of potassium salts and adjacent tailings.

From an ecological point of view, the fact that any rocks that contain water-soluble salts and are located above the Earth's surface and aquifer will inevitably undergo intense hypergenic changes and salt components will be carried into the environment.

Observations show that the existing means of recultivation of dumps and tailings are not effective, and man-made objects in their current form, in principle, cannot perform the function of burying easily soluble salts. Accordingly, they will remain a source of salt supply to the environment for a very long time to come.

But the deposits stored in tailings are not wastes in the classical sense. With the right approach, they, like the brines that fill the Dombrovsky quarry, can be efficiently processed. Promising products of such activities are the following: technical salt, kalimagnesia and concentrated magnesium chloride solution or crystalline bischofite. This spectrum is due to the historical fact that during the period of operation of the quarry (19652008), due to the imperfection of technology, only $25 \%$ of the useful components are used out of one ton of ore. The remaining $75 \%$ of mineral raw materials were directed to waste, which were stored in tailings (Dovhyi and Korzhnev, 2014) and now needs to be evaluated in terms of their use as non-traditional cheap mineral raw materials. The results of the latter can be the basis for the development of options for their further use and the continuation of research work on the site as a whole.

The prospects for processing brines in flooded quarries are described by the possibility of extracting from $1 \mathrm{~m}^{3} 115 \mathrm{~kg}$ of potassium-magnesium sulfate fertilizer - kalimagnesia, $210 \mathrm{~kg}$ of technical salt and $120 \mathrm{~kg}$ of $32 \%$ magnesium chloride solution. And given the fact that currently in the abandoned pit, which is in the stage of selfflooding, more than 10 million $\mathrm{m}^{3}$ of brine has already been accumulated. The prospects for production are quite large, as well as the amount of possible net income (according to preliminary estimates of authors - about 36.5 million $€$ per year).

Over the past 10 years, several attempts have been made to put the brine processing ideas into practice. In 2011, a proposal was made by the Italian company Vomm (Milan) to process the saltwater that had been accumulated in the Dombrovsky quarry. The project provided for the installation of ten special modules and the processing of 3 million $\mathrm{m}^{3}$ of brine per year. The cost of technical salt obtained as a result of this approach, calculated by experts, was $52 €$ per ton, and if it was sold in Europe, the net profit could be $€ 10$ million a year. In 2018, Kalush Salt Company LLC initiated a similar project. It provided for the processing of smaller volumes of brine ( 1 million $\mathrm{m}^{3}$ per year) but a larger range of products (rock salt, kalimagnesia and caustic soda). However, in each case, the proposals encountered a number of obstacles, including legal and economic ones, as a result of which they have never been implemented, although the prospects were not in doubt. 
The research compared these projects, particularly their quantitative and financial results (possible volumes of processed brines, technologies, required investments, payback, etc.). The values (declared in the projects) have become the fundamental arguments justifying the expediency of reviewing the effectiveness of approaches and methods of brine processing in Ukraine, primarily, those that are based on technologies for their demineralization.

Brine evaporation systems are currently considered to be the most promising and realistic in Ukraine. This is due to the possibility of obtaining marketable products using a minimum of equipment. However, the development of the salt industry in the world and the urgency of research in the field of extraction from complex solutions of brines of a number of useful components have significantly accelerated the modernization of technological approaches to this activity. The desire to qualitatively convert the removed useful components into a marketable product helped to intensify the search for new opportunities to address the issue, which would be both attractive to investors and safe for the environment (Brine Treatment, 2020; Ji X. et al., 2010; Pramanik et al., 2017).

In particular, it gave the impetus to the development of membrane technologies. The analysis of their variations (premature desalination (reverse osmosis), membrane purification and electrodialysis) gives grounds to consider their introduction at a number of Ukrainian facilities (Dombrovsky quarry inclusive) as a promising initiative. To a large extent, this is due to the possibility of creating not only conditions for the growth of the revenue potential of the study area but also significantly contributes to the restoration of the disturbed ecobalance of the territories.

As the example of the given projects, the contrast between traditional methods and more technological ways of brine management is obvious. This is reflected both in the level of economic costs and in the productivity of extraction of useful components.

In order to prove the feasibility of using the brines of the Kalush-Golinsky deposit as a source of additional raw materials and the cost-effectiveness of this approach, an experiment was conducted. For the Dombrovsky quarry, combined conditions were modelled. They included the following:

- the use of electrodialysis, as one of the most high-tech methods of brine processing in the world, the cost of which reaches $10.05 \$ / \mathrm{m}^{3}$ or $8.28 € / \mathrm{m}^{3}$ (according to the exchange rate as of 11.06.2021);

- the amount required for project implementation proposed in 2018, investments (100€ million);

- as well as the annual restriction of direct processing of brines by 1 million $\mathrm{m}^{3}$, which was also envisaged by the previous project, but under the conditions of using traditional technologies.

Based on these initial data, key financial indicators were calculated. These include profitability index (PI) (1) and net present value (NPV) (2) (USAID, 2012). Interpretation of the obtained results made it possible to draw conclusions about the profitability of the described approach to work with brines.

In addition, for enhanced highlighting of possible changes in the studied parameters, which describe the efficiency level of the projects of this type, three variations of the annual discount rate were considered, taking into account its fluctuations over the past three years. The use of all these data in relation to current world prices for technical salt and mineral fertilizers, in particular potash, as well as the volume of their possible extraction from brines demonstrated the results presented in Tab. 1 and Tab. 2.

$$
P I=\frac{\sum_{k=1}^{n} \frac{N C F_{k}}{\left(1+r_{k}\right)}}{\sum_{j=1}^{m} \frac{I_{j}}{\left(1+r_{j}\right)^{j}}}
$$

where $n$ is the forecast period, years; $k$ - the year in the forecast period; $N C F_{k}$ - net operating cash flow (income) per year $k$, million $€ /$ year; $r_{k}$ - annual discount rate per year $\mathrm{k}, \% ; m$ - number of years during which the investment is planned, years; $j$ - the year in which the investment is made; $I_{j}$ - investments (expenses) per year $j$, million $€ ; r_{j}$ - the annual discount rate in the year $j, \%$.

Tab. 1. The value of the project profitability index

\begin{tabular}{|c|c|}
\hline Annual discount rate & PI \\
\hline $8 \%$ & 4,28 \\
\hline $14 \%$ & 4,67 \\
\hline $19 \%$ & 4,94 \\
\hline
\end{tabular}

$$
N P V=\sum_{k=1}^{n} \frac{N C F_{k}}{\left(1+r_{k}\right)}-\sum_{j=1}^{m} \frac{I_{j}}{\left(1+r_{j}\right)^{j}}
$$


Tab. 2. The value of indicator of net present value

\begin{tabular}{|c|c}
\hline Annual discount rate & NPV, mil. $€$ \\
\hline $8 \%$ & 258,68 \\
\hline $14 \%$ & 251,37 \\
\hline $19 \%$ & 244,42 \\
\hline
\end{tabular}

The obtained results definitely correspond to the dependencies (PI> $1, \mathrm{NPV} \geq 0$ ) defined in the relevant state and technical documents (USAID, 2012), which describe the projects as those having high efficiency. A significant contribution to the positive assessment of the proposed approach is made by a low variability of the obtained indicators, even in the event of fluctuations in economic development.

The use of technologically innovative solutions in the presented experimental project, among other things, was proposed in order to expand the prospects for sustainable development of the region. First of all, introducing the latest technologies for brine processing will significantly impact the overall efficiency of the project. In particular, due to the modernization of the methodological approach, it is possible to reduce significantly the payback period ( 5 years - in the proposed project in 2018, 3 years in case electrodialysis is applied) and increase the total income for the project period. Secondly, the transition of domestic approaches to a new technical and economic level is a logical solution for the region, which is in urgent need to reduce the negative impact on the geological environment. And conceptual changes in this area will significantly contribute to the approach to compliance with the priority world concept: "cost-effective technology with zero discharge of pollutants."

In addition, any transformations in mining regions on sustainable development grounds provide for the specification of their functional load in the country's economy. However, in the Pre-Carpathian Downfold, a wasteful attitude to such resources as man-made deposits is observed, which is critically irrational. To a large extent, this is due to the possibility of an increase in export volumes of marketable products obtained as a result of brine processing, which is currently very relevant.

Another proof of the expediency of promoting the implementation of such projects is the acceptability of the indicators calculated in the study for entrepreneurs as well as for public partners. In particular, such projects will achieve a number of socio-economic goals. Among the latter are: creating conditions for innovative development of the internal market, improving the investment climate and achieving European standards of living, including environmental safety.

All this convincingly proves the feasibility of using brines of the Pre-Carpathian Downfold (including Kalush-Golinsky deposit) as additional raw materials to improve the ecological and economic condition of the region. In particular, the economic efficiency of the proposed approach is confirmed. However, like any innovation, the modernization of the brine approach is accompanied by a number of aspects that need to be carefully monitored and controlled. Including:

1. The need for active implementation of various environmental programs on the state as well as local level with a clear distribution of funding for measures aimed at protecting and restoring certain components of the geological environment (Kosharna, 2019). Any programs of ecological rehabilitation of the region should be based on a permanent forecast model of the geological environment, which should be based on well-established monitoring systems of its various components (hydrogeological, engineering-geological, seismic, soil and surface water pollution, etc.). Thus, financial resources will be allocated more rationally, and prevention and solution of specific environmental problems that may arise in the case of implementation of the greatest environmental risks calculated in such a model will be more effective.

2. The emergence of a set of social problems associated with the impact of technological innovation on the socio-political component of regional sustainable development (Korzhnev, Kurilo, Kosharna, 2021): the number of jobs in enterprises and changes in these figures associated with the introduction of new technologies or in case of unprofitable enterprises, wages and social protection of workers, creation of new jobs and employment of dismissed workers, injuries - all the above mentioned should be foreseen and reflected in state statistics. This is especially important for developing a large-scale, long-term program for restructuring the salt industry in the Pre-Carpathian Downfold.

3. Impossibility of momentary transition to new technologies and revision of the entire system of functioning of the existing infrastructure of districts that have appropriate prospects for brine processing. For these reasons, the authors consider optimizing the work with highly mineralized waters by combining technologies into hybrid systems to be the rational solution to the problem. Gradual combination of traditional methods with the latest ones (Rudko and Petryshyn, 2014), accompanied by careful monitoring of all key indicators of project effectiveness in a short time, will allow to obtain statistical confirmation of the rationality of the approach and ensure a smooth transition of the domestic industry to a new technical and economic level. 


\section{Conclusions}

Under the conditions of objective selection, the implementation of projects of this direction is a comprehensive solution to the economic and environmental problems. The result of such implementation may be a simultaneous increase in the extraction of raw materials from brines and thus reduce the pressure on the environment. It also gives impetus to the development of innovation in enterprises and helps to increase the competitiveness of products on the world market. Under such conditions, finding partners abroad will be easier, and the sale of Ukrainian exports (the same kalimagnesia) will positively impact the country's economy, as the growth of foreign exchange resources will curb inflation.

To achieve this, a strategy must be defined, and a clear and transparent program for further balanced development of the region must be drawn up. Obviously, this should be based on:

- previously developed and implemented system for monitoring the deformation of the Earth's surface, levels and chemical composition of groundwater and surface water;

- the created forecast model of developing dangerous ecological and geological processes in flooding zone of salt-mining complex industrial objects;

- implemented system of measures for alternative water supply to the population at the expense of underground sources protected from pollution.

Consideration of polymineral brines of the Pre-Carpathian Depression not only as the root causes of ecological imbalance but also as a potentially profitable project for investment is far-reaching given the opportunities offered by such an approach.

\section{References}

Amosha O., Bulieiev I., Zemliankin A., et al. (2017). Ukrainian Industry - 2016: state and prospects of development. Institute of Industrial Economics

Brine Treatment, available at: https://www.lenntech.fr/processes/brine-treatment.htm

Cojean R., Franco N., Lazarevic J.-C., et al. (2005). The post-mining context at Decazeville-Firmi concession (Aveyron, France): analysis of impacts resulting from the cessation of pumping at the central shaft. Survey of various scenarios related to the water level of the Pit lake in the Grande Decouverte. Post mining Symposium, Nov 2005, Nancy, France. Retrieved January 25, 2020, from https://halineris.archives-ouvertes.fr/ineris-00972519

Chonka I., Levytska Yu., Halla-Bobyk S. (2019). Ecological circumstance in Kalush-Holynsky field around extraction of mineral salts: impact on the soil and water of surrounding areas. Science. Bulletin of Uzhhorod. University: Chemistry Series. 2(42), 96-104.

Dovhyi S., Korzhnev M. (Ed.). (2013). Criteria of ecological, geological and economic assessment and wastes' mineralogy of the mining and metallurgical complex of Kryvbas. Kyiv: Nika-Center. C. 228.

Dovhyi S., Korzhnev M. (Ed.). (2014). Mineral complex and sustainable development of Ukraine. Kyiv, 236.

Holovchak V. (2012). Transformation of geosystem's components in the process of environmental management at the Kalush-Golynsky deposit of potassium ores. 1, p. 57-62.

Ji X., Curcio E., Al Obaidani S., Di Profio G., Fontananova E., Drioli E. (2010). Membrane distillationcrystallization of seawater reverse osmosis brines. Sep. Purif. Technol. 71, p. 76-82. doi: 10.1016/j.seppur.2009.11.004

Korzhnev M., Kurilo. M., Kosharna S. (2021). Approaches to sustainable development of the Kryvyi Rih iron ore basin planning at the post-mining stage KNU Bulletin. Geology, 92, 79-87.

Kosharna, S. (2020). Geological and economic aspect of brine processing as a tool for normalization of the PreCarpathian Depression's natural balance in the context of general monitoring of the region's ecological state. Conference Paper. XIV International Scientific Conference on Monitoring of Geological Processes and Ecological Condition of the Environment, Kyiv, November 10-13, 2020, Volume 2020, p.1 - 5 https://doi.org/10.3997/2214-4609.202056046

Kosharna S. (2019). Geological and economic estimation of iron-ore deposits of the Kryvyi Rih basin on the stage of the intensive use and exhaustion of reserves. Extended abstract of $\mathrm{PhD}$ thesis (Economic geology). Kyiv.

Kuzmenko E.D., Bagrii S.M. (2015). Ecological and geological monitoring on the territory of Kalush mining district - plans and realities. Proceedings of the XII International Conference. "Geoinformatics: theoretical and applied aspects". May 13-16, 2013. - Kyiv: Kyiv National Taras Shevchenko University. C.1-6.

Kuzmenko E.D., Bagriy S.M. (2009). The threat of river water breakthrough in Dombrovsky open pit of KalushGolinsky potassium salt deposit - reality or fantasy?. Proceedings of IX International Scientific Conference "Monitoring of geological processes". Kyiv, 14-17 October 2009. K., 2009. C. 145 - 147. 
Malkova Y. O., Bobkov V. M., Dolin V. B. (2020), Modeling the kinetics of dissolution of minerals of saline rocks of the Dombrovsky quarry // Mineralogical Journal. - 2020. - 42, № 4. - C. 60-68. Web of science

Malkova Y. A., Dolin V. V., Bobkov V. M. (2020), Experimental modeling of convection-diffusion mass transfer in brines of the Dombrovsky quarry (Kalush, Ivano-Frankovsk Region) // Mineral Resources of Ukraine. - 2020. - № 4. - C. 22-27.

Malkova Y., Dolin V., Yakovlev E. (2020), Ecological and technogenic regularities of the formation of the Dombrovsky quarry brines // Bulletin of the Kiev National Taras Shevchenko University. Geology Series. - 2020. - № 4(91). Web of science

Malkova Y., Dolin V., Yakovlev Y., Kuzmenko E., Shcherbak O. (2021). Conjugated effects between surfaceand groundwater mineralization within the drainage zone of Dombrovsky quarry // Conference Proceedings, Geoinformatics: Theoretical and Applied Aspects 2021 May 2021.

Malovanyi M., Savchuk L. (2013). Minimization strategy of ecological risk by introducing a complex recycling technology of brines and solid waste of potassium production in Kaluzh industrial region. Visnyk of KrNU. 1(78), p. 109-113.

Maniuk O. (2009). Science and practical principles of environment protection from contamination with highly mineralized brines (on the example of Calush-Golyn deposit of potassium salts): Abstract of cand. tech. sciences: 21.06.01 (Environmental safety) [Ivano-Frankivsk National Technical University of Oil and Gas]. Ivano-Frankivsk, 19.

Maniuk O., Melnyk O., Semchuk Ya. (2009). The underground burial of highly mineralized brines of the Kalush-Golynsky potassium salts deposit within exhaust by hydrocarbon's development deposits as an effective measure of environmental protection. Scientific Bulletin of Ivano-Frankivsk National Technical University of Oil and Gas. 1(17), p. 142-147.

Maniuk E.R., Semchuk J.M. (2007). Study of features of geological structure and hydrogeological conditions of Kalush-Golinsky potassium salt deposit in order to design the disposal site of highly mineralized brines. Scientific Bulletin of Ivano-Frankivsk National Technical University of Oil and Gas. 2007. №1. C.21

Pavlyuk V.I. (2010). Features of monitoring of exogenous geological processes within the spread of technogenically disturbed salt-bearing miocene deposits of Predkarpattya. Proceedings of the 5th Scientific and Practical Conference "Ecological safety of technogenically disturbed regions". Yalta, 2010. C. 36-37.

Pramanik B.K., Jegatheesan V., Shu Li. (2017). A review of the management and treatment of brine solutions.Environmental Science: Water Research \& Technology. 3(4), 625658. doi:10.1039/C6EW00339G

Program for the Development of Public-Private Partnerships in Ukraine; Practical Guide for the Preparation of Techno-Economic Assessment. USAID. (2012). Available at: http://ppp-ukraine.org/wpcontent/uploads/2015/03/PracticalGuide.pdf.

Rudko G., Petryshyn V. (2014). Stabilization' problems of ecological situation in Kalush mining district. Ecology and industry. 7, p. 163-186.

Sardinha I., Carolino J., Mendes I. \& Verga Matos P. (2010). The rehmine research project: the threefold value of São Domingos abandoned mine rehabilitation in southern Portugal. WIT Transactions on Ecology and the Environment, 141, 28-38, doi:10.2495/BF100031, WIT Press: ISSN 1743-3541, Retrieved January 18, 2020, from www.witpress.com

Sklenicka P., Prikryl I., Svoboda I.,Lhota T. (2004). Non-productive principles of landscape rehabilitation after long-term opencast mining in north-west Bohemia. Journal of The South African institute of Mining and Metallurgy, 83-88.

State Fiscal Service of Ukraine, available at: http://sfs.gov.ua/ms/f11

Zhuravel M., Klochko P., Bulbas V., Lisovyi G. (1998). Assessment and prognostication system of drinking groundwater and surface water sanitary and hygienic conditions in the areas of OJSC "Ukrnafta" location. Oil and gas industry. 3, p. 5-11. 